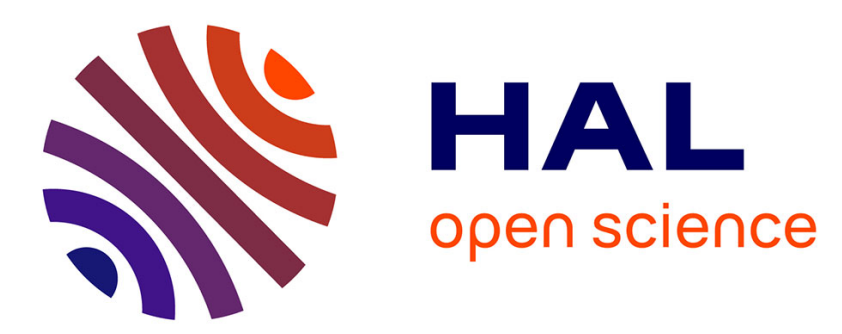

\title{
On some advanced Thermo-Mechanical models for saturated clays
}

Pengyun y Hong, Jean-Michel Pereira, Anh Minh A.M. Tang, Yu-Jun Cui

\section{To cite this version:}

Pengyun y Hong, Jean-Michel Pereira, Anh Minh A.M. Tang, Yu-Jun Cui. On some advanced ThermoMechanical models for saturated clays. International Journal for Numerical and Analytical Methods in Geomechanics, 2013, 37 (17), pp.2952-2971. 10.1002/nag.2170 . hal-00926922

\section{HAL Id: hal-00926922 \\ https: / hal-enpc.archives-ouvertes.fr/hal-00926922}

Submitted on 8 May 2019

HAL is a multi-disciplinary open access archive for the deposit and dissemination of scientific research documents, whether they are published or not. The documents may come from teaching and research institutions in France or abroad, or from public or private research centers.
L'archive ouverte pluridisciplinaire HAL, est destinée au dépôt et à la diffusion de documents scientifiques de niveau recherche, publiés ou non, émanant des établissements d'enseignement et de recherche français ou étrangers, des laboratoires publics ou privés. 


\title{
On some advanced Thermo-Mechanical models for saturated clays
}

\author{
P.Y. Hong, J.M. Pereira*, A.M. Tang, Y.J. Cui \\ Université Paris-Est, Laboratoire Navier (UMR 8205), CNRS, ENPC, IFSTTAR, F-77455 Marne-la-Vallée, France.
}

\begin{abstract}
SUMMARY
This paper aims to evaluate the performance of several recent constitutive models in simulating the thermo-mechanical behaviour of saturated clays. A classic thermo-mechanical test on natural Boom Clay, commonly used in constitutive modelling was first clarified. Different methods commonly used to measure volumetric strain in drained heating tests were then discussed. Models evaluation was performed in terms of thermodynamic and elasto-plastic requirements. The capability of the models to capture the observed behaviour was assessed on the basis of the experimental evidence. It was shown that all the models provide reasonable predictions of the thermo-mechanical behaviour of saturated clays. However, each constitutive model has its own limitations or unclear points from the theoretical point of view.
\end{abstract}

KEY WORDS: thermo-mechanical behaviour; saturated clay; constitutive model; theoretical analysis.

\section{INTRODUCTION}

Relevant thermo-mechanical constitutive models for clays are important in analysing geomechanical problems such as nuclear waste geological disposals, reservoir engineering, etc.

Various thermo-mechanical models have been developed allowing the description of the thermomechanical behaviour of saturated clays, though with different theoretical approaches. The thermomechanical behaviour of clays has been discussed in detail by several researchers (e.g. [1, 2, 3, 4]) based on the available experimental results. The main features of the thermo-mechanical behaviour of saturated clays are summarized below:

1. the volume change upon heating depends on the overconsolidation ratio (OCR): at low OCR values (close to 1), only thermal contraction occurs, but at high OCR values there is first thermal expansion followed by thermal contraction;

2. the soil compressibility is independent of temperature;

3. the preconsolidation pressure decreases with increasing temperature;

4. the preconsolidation pressure at a given temperature increases after a heating-cooling cycle due to the thermal hardening effect.

Several constitutive models for describing the thermo-mechanical behaviour of soils were proposed in the last two decades. Hueckel et al. [5, 6] developed the first thermo-mechanical models (TM) by extending the well-known Modified Cam Clay model (MCC). A yield surface accounting for temperature effects on the preconsolidation pressure was introduced to reproduce the plastic strains due to temperature changes. It was shown however that this model is not capable to predict the behaviour of soils in overconsolidated state. Robinet et al. [7] established a thermo-elasto-plastic

*Correspondence to: École des Ponts ParisTech, Laboratoire Navier - CERMES, 6-8 av. B. Pascal, 77455 Marne-laVallée cedex 2, France. Email address: jeanmichel.pereira@enpc.fr

Contract/grant sponsor: The first author gratefully acknowledges Chinese Scholarship Council for grant scholarship number: 2009609031 
model to govern the macroscopic behaviour using a microscopic mechanism, in which irreversible thermal strains were originally introduced to control thermal softening. Graham et al. [8] proposed a non-isothermal modified Cam Clay model in an accessible semi-graphical framework rather than the mathematical framework used by Hueckel and co-workers but still without considering thermoplastic behaviour in overconsolidated state. Cui et al. [3] introduced an extra yield surface in the plane of mean effective stress $p^{\prime}$-temperature $T$, namely thermal yield surface (TY), to better describe the thermal plastic strains especially in the overconsolidated state. In their models, the conventional yield limit which characterises the isotropic plastic mechanism and which gives the preconsolidation pressure as a function of temperature is referred to as the loading yield surface (LY). Consequently, a double yield surface with TY and LY delimits the reversible elastic domain in the $\left(p^{\prime}, T\right)$ plane. Following this development, multi-yield surfaces have been adopted in the recent constitutive models. Abuel-Naga et al. [9] developed a thermo-mechanical model using an approach similar to Cui et al.'s one [3]. Laloui and François [4, 10] developed a thermoplastic model by extending the work of Hujeux [11] based on the multi-surface plasticity theory. Furthermore, to improve the thermo-mechanical behaviour observed at high and intermediate overconsolidation ratios, Laloui and François [4, 10] applied the bounding surface theory to the isotropic plastic mechanism. This permits to describe the occurrence of plastic strains inside the conventional yield domain in the sense of classic plasticity theory. These different thermo-mechanical models for saturated clays present certain advantages and limitations that will be discussed later.

To investigate the thermally induced volume changes, extensive experimental work has been done by applying heating-cooling cycles on soils with different OCRs [1, 12, 13, 14, 15]. The thermo-mechanical test (TBoom9) carried out by Baldi et al. [1] on natural Boom Clay is often used to validate the performance of thermo-mechanical models in predicting thermally-induced plastic volumetric strains. However, it has been observed that the precise loading path and the experimental results obtained during this test have not been accurately considered. This could lead to misinterpretations of the experimental results, and thus make the validation of constitutive models questionable.

The present paper aims at clarifying the results from the thermo-mechanical experiments conducted on natural Boom Clay by Baldi et al. [1] and assessing the performance of the recent thermo-mechanical models proposed by Cui et al. [3], Abuel-Naga et al. [9], and Laloui and François $[4,10]$. For the clarification of the experimental data, the experimental procedure was presented and a discussion on the methods of calculating the drained thermal volumetric strain was made. For the models' performance assessment, the constitutive modelling approaches were briefly reviewed and compared; the capabilities of the three models to describe the observed experimental behaviour were analysed by simulating two sets of tests with combined thermo-mechanical loadings on natural Boom Clay; these models were analysed from a fundamental point of view, in terms of elastoplasticity and thermodynamic consistency.

\section{THERMO-MECHANICAL TEST ON NATURAL BOOM CLAY}

Baldi et al. [1] reported a thermo-mechanical test on natural Boom Clay (TBoom9) sampled at 240 $\mathrm{m}$ depth in the underground research laboratory of Mol, Belgium. The preconsolidation pressure was evaluated at $6 \mathrm{MPa}$ from isotropic compression tests. The thermo-mechanical loading path followed in the test is shown in Figure 1, and can be summarised as follows:

1. The specimen was first saturated under a constant mean effective stress of $2 \mathrm{MPa}$ (point A) which was close to the in situ effective stress of $2.3 \mathrm{MPa}$. It was then loaded up to a mean effective stress of $4 \mathrm{MPa}$ (path A-B) and unloaded to $1 \mathrm{MPa}$ at a constant temperature of $21.5^{\circ} \mathrm{C}$ (path B-C).

2. A heating-cooling cycle of $21.5^{\circ} \mathrm{C}-95^{\circ} \mathrm{C}-21.5^{\circ} \mathrm{C}$ (path C-D-E) was applied under a constant mean effective stress of $1 \mathrm{MPa}$. 


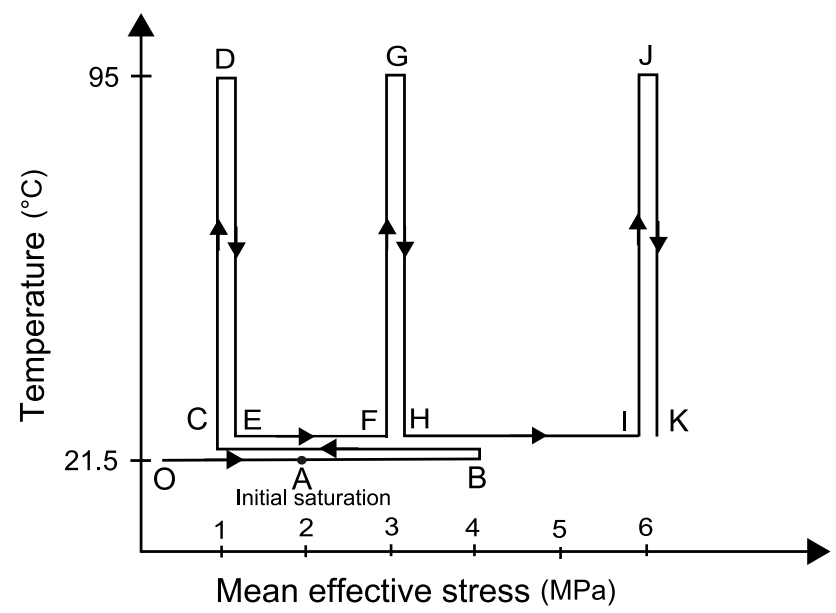

Figure 1. Isotropic thermo-mechanical loading path followed during TBoom9 test on natural Boom Clay (adapted from Baldi et al. [1]).

3. Mechanical isotropic re-loading up to $3 \mathrm{MPa}$ was applied (path E-F) and followed by the same heating-cooling cycle as in step 2 (path F-G-H) under a constant mean effective stress of 3 MPa.

4. Mechanical isotropic re-loading up to $6 \mathrm{MPa}$ (path $\mathrm{H}-\mathrm{I}$ ) was applied and followed by the same heating-cooling cycle as in step 2 or 3 (path I-J-K) under a constant mean effective stress of 6 $\mathrm{MPa}$.

In the data reported by Baldi et al. [1], the drained thermal volumatric strain was calculated following two different methods. Thus, two different series of experimental results for the same test were presented by the authors.

In Method 1, the soil was assumed to be thermo-mechanically isotropic. Drained thermal volumetric strain was calculated as three times the axial strain measured by an external displacement transducer: $\varepsilon_{v}=3 \varepsilon_{a}$.

In Method 2, the drained thermal volumetric strain was computed by subtracting the calculated thermal expansion attributed to both the pore water and the solid phase from the measured volume of water expelled from the soil sample. This method was firstly suggested by Campanella and Mitchell [16] and then improved by Baldi et al. [1]. Campanella and Mitchell [16] gave the following expression for the drained thermal volumetric strain:

$$
\begin{aligned}
\varepsilon_{v} & =\frac{\left(\Delta V_{m}\right)_{\Delta T}}{V_{0}} \\
& =\left(\Delta V_{D R}\right)_{\Delta T}-\left(\Delta V_{s}\right)_{\Delta T}-\left(\Delta V_{w}\right)_{\Delta T}
\end{aligned}
$$

where $\left(\Delta V_{m}\right)_{\Delta T}$ is the volume change of the whole specimen, $V_{0}$ is the initial volume of the specimen, $\left(\Delta V_{D R}\right)_{\Delta T}$ is the volume of the water drained out, $\left(\Delta V_{s}\right)_{\Delta T}$ and $\left(\Delta V_{w}\right)_{\Delta T}$ are the volume changes due to a temperature increment $\Delta T$ of the solid phase and the pore water respectively. The last two terms are calculated according to:

$$
\left(\Delta V_{s}\right)_{\Delta T}=\alpha_{s} V_{s} \Delta T
$$

and considering the thermal properties of free water:

$$
\left(\Delta V_{w}\right)_{\Delta T}=\alpha_{w} V_{w} \Delta T
$$

where $\alpha_{s}$ and $\alpha_{w}$ are the thermal expansion coefficients of the solid phase and free water respectively. $V_{s}$ and $V_{w}$ stand for the volumes of solids and pore water respectively. 
Considering adsorbed water only in dense plastic clays and using the double-layer theory instead of Equation 4, Baldi et al. [17] proposed the following expression for the volume change due to the thermal expansion of pore water:

$$
\left(\Delta V_{w}\right)_{\Delta T}=V_{0} \Delta v_{a} S_{s} \rho_{d} \Delta T
$$

where $\Delta v_{a}$ is the volume of expanded adsorbed water per unit surface area of mineral solid and per Kelvin. $S_{s}$ is the specific surface of the soil, and $\rho_{d}$ is the dry unit mass of the soil.

Since in reality the pore water is in the form of both free water and adsorbed water, a special procedure was defined to evaluate the actual thermal expanded volume of the pore water $\left(\Delta V_{w}\right)_{\Delta T}$ in Equation 1 without applying Equation (3) for free water only or Equation (4) for adsorbed water only. Two specimens of similar physical properties were prepared, one of which (TBoom9) was trimmed vertically to the bedding plane and the additional one (TBoom13) was trimmed horizontally to the bedding plane. In TBoom13, a heating and cooling cycle was applied under a constant mean effective stress of $p^{\prime}=3 \mathrm{MPa}$. During the corresponding heating-cooling cycle under the mean effective stress of $3 \mathrm{MPa}$ (Figure 1, path F-G-H), the lateral strain $\varepsilon_{l}$ of TBoom9 was assumed to be identical to the axial strain measured in test TBoom13. Thus, the thermal volumetric strain $\varepsilon_{v}$ in path F-G-H of TBoom9 could be calculated using $\varepsilon_{v}=\varepsilon_{a}+2 \varepsilon_{l}$, where the axial strain $\varepsilon_{a}$ and lateral strain $\varepsilon_{l}$ were deduced from the measures of the axial displacement during the two tests TBoom 9 and Tboom13, respectively. Considering the calculated thermal volumetric strain $\varepsilon_{v}$ along path F-G-H of test TBoom 9 and the thermal expansion parameter of the solid phase of natural Boom Clay $\left(\alpha_{s}\right)$, the actual thermal expanded volume of the pore water $\left(\Delta V_{w}\right)_{\Delta T}$ was obtained according to Equations 1 and 3.

Assuming that the actual thermal expanded volume of the pore water $\left(\Delta V_{w}\right)_{\Delta T}$ was the same for all the three heating-cooling cycles (i.e, paths C-D-E, F-G-H, I-J-K), the volumetric strain was calculated from the drained pore water volume according to Equation 1. The volumetric strain thus obtained is plotted in Figure 2 (solid line).

The volumetric strain calculated by Method 1 and Method 2 are compared in Figure 2. The difference was attributed to the thermo-mechanical anisotropy of natural Boom Clay. The former volumetric strain was referred to as isotropic volumetric strain and the latter as anisotropic volumetric strain.

Comparing these two methods for estimating the volumetric strain, it appears clearly that Method 1 constitutes a much simpler solution which assumes the thermo-mechanical isotropy of natural Boom Clay. However, this assumption does not hold true since available experimental data (including TBoom9 test) showed significant thermo-mechanical anisotropy for this material. Thus, the results obtained from Method 1 are not accurate and do not reflect the actual volumetric thermo-mechanical behaviour of natural Boom Clay. As opposed to Method 1, Method 2 is more sophisticated and should provide more accurate results. It should however be noted that applying the volumetric change of pore water from a single heating-cooling cycle (F-G-H) to the three heatingcooling cycles would also induce some errors.

Volume changes during heating-cooling cycles is an important feature in the thermo-mechanical behaviour of soils. The existence of various interpretations of TBoom 9 test as reported here (in terms of loading path and volumetric strain estimation) may lead to different choices when developing or calibrating constitutive models.

\section{THERMO-MECHANICAL MODELS}

In this section, the thermo-mechanical models proposed by Cui et al. [3], Abuel-Naga et al. [9], Laloui and François $[4,10]$ are reviewed. In the following, these models are referred to as Model C, Model A and Model L respectively. The main equations governing the thermo-mechanical behaviour are briefly summarized in Table I. Only isotropic stress states are considered. Some of the original notations are changed to avoid confusion between the three models. 


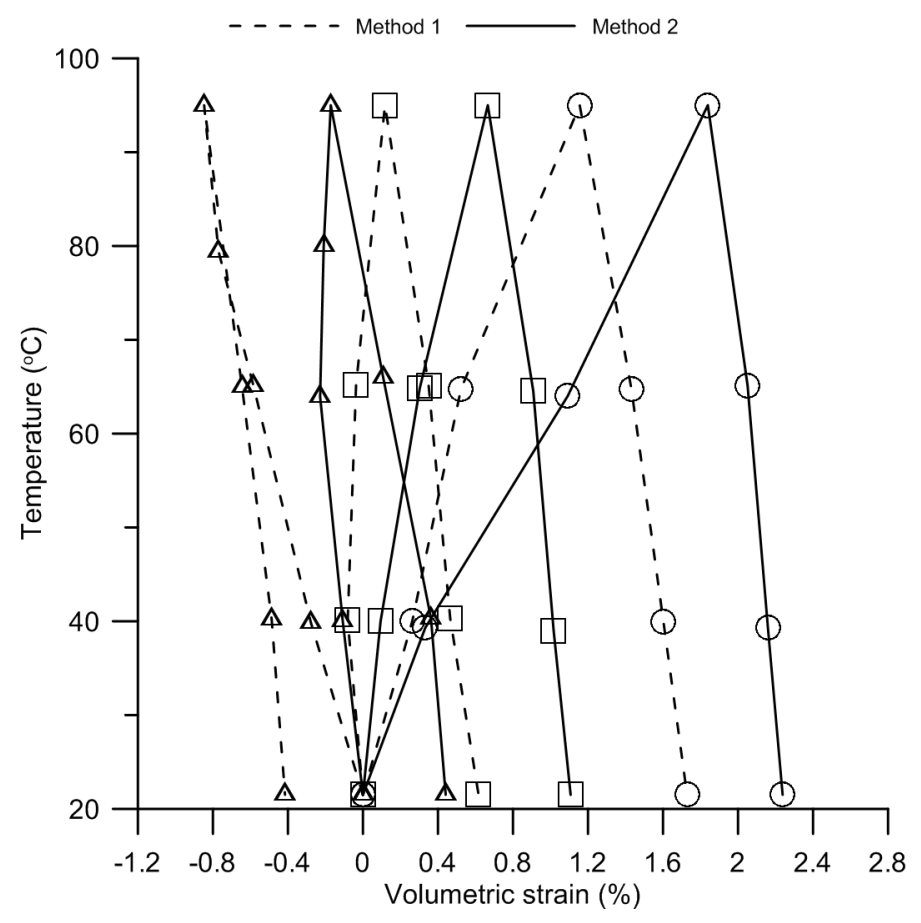

Figure 2. Volumetric strain for thermo-mechanical test TBoom9 (from Baldi et al. [1]) obtained from two methods: Method 1 - volumetric strain calculated as three times the axial strain; Method 2 - volumetric strain calculated from the volume of drained out water and the thermal expansion of pore water and solids; $(\triangle=$ path C-D-E; $\square$ = path F-G-H; $\bigcirc=$ path I-J-K ).

\subsection{Thermo-mechanical elastic behaviour}

In all the three models, the total elastic volumetric strain increment $\left(d \varepsilon_{v}^{e}\right)$ consists of two parts, due to either thermal or mechanical loadings, respectively. This increment reads as follows for Models $\mathrm{C}$ and Model L:

$$
d \varepsilon_{v}^{e}=\alpha d T+\frac{d p^{\prime}}{K}
$$

and for Model A:

$$
d \varepsilon_{v}^{e}=\frac{\alpha_{A}}{T} d T+\frac{d p^{\prime}}{K}
$$

where $\alpha$ and $\alpha_{A}$ are the volumetric thermal expansion coefficients of soil in Models $\mathrm{C}$ or $\mathrm{L}$ and Model A respectively, $K$ is the bulk modulus which is temperature independent. 


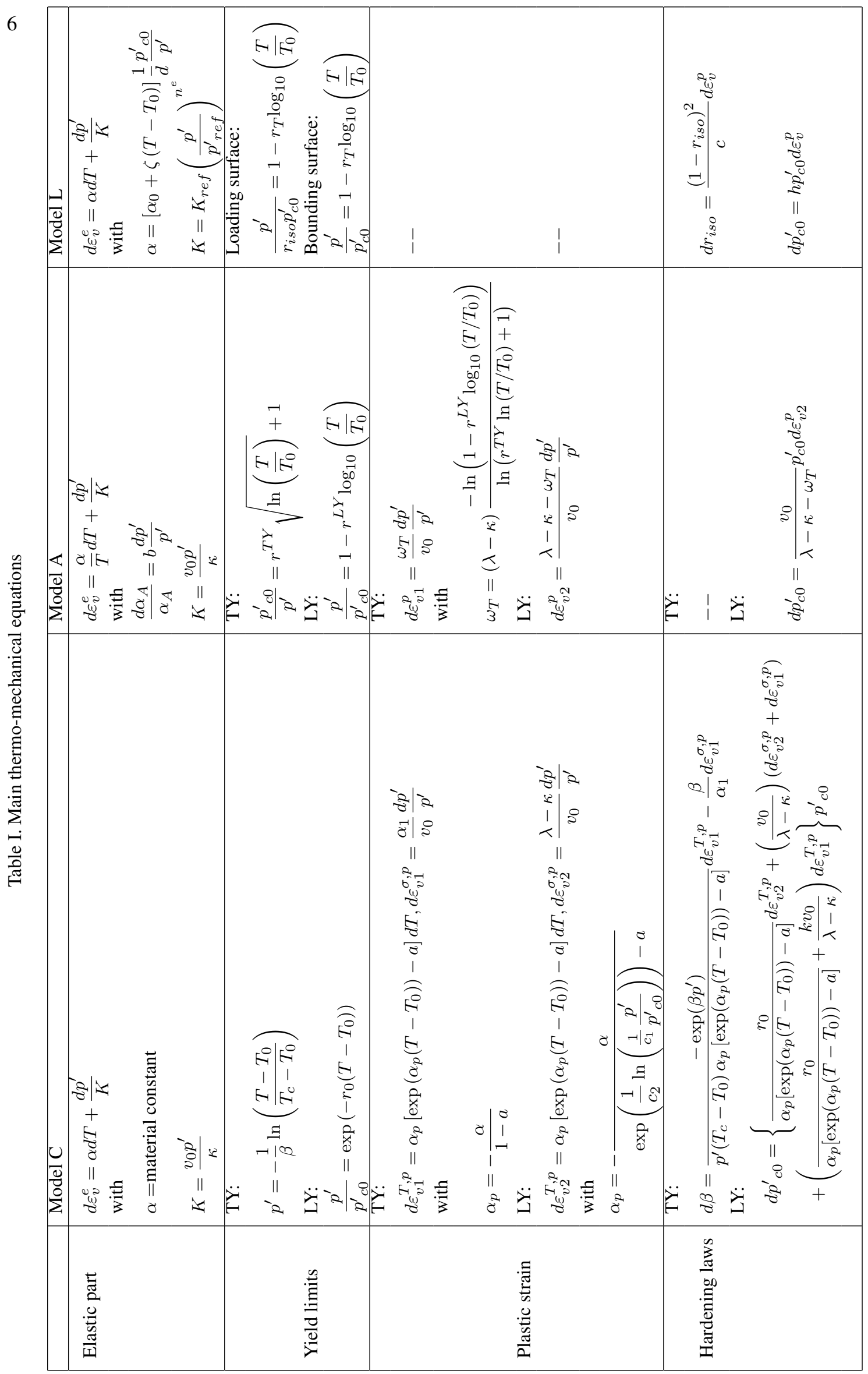


Table II. Volumetric thermal expansion coefficient for natural Boom Clay (TBoom9) obtained from volumetric strains estimated using Method 1 and Method 2

\begin{tabular}{|c|c|c|c|c|c|c|}
\hline & \multicolumn{2}{|c|}{$\begin{array}{c}\alpha \text { at } p^{\prime}=1 \mathrm{MPa} \\
\left(\times 10^{-5} /{ }^{\circ} \mathrm{C}\right)\end{array}$} & \multicolumn{2}{c|}{$\begin{array}{c}\alpha \text { at } p^{\prime}=3 \mathrm{MPa} \\
\left(\times 10^{-5} /{ }^{\circ} \mathrm{C}\right)\end{array}$} & \multicolumn{2}{c|}{$\begin{array}{c}\alpha \text { at } p^{\prime}=6 \mathrm{MPa} \\
\left(\times 10^{-5} /{ }^{\circ} \mathrm{C}\right)\end{array}$} \\
\hline Temperature range & Method 1 & Method 2 & Method 1 & Method 2 & Method 1 & Method 2 \\
\hline $21.5^{\circ} \mathrm{C}-40^{\circ} \mathrm{C}$ & -3.85 & -4.23 & -8.15 & -4.90 & -6.83 & -4.23 \\
\hline $40^{\circ} \mathrm{C}-65^{\circ} \mathrm{C}$ & -6.32 & -9.94 & -4.61 & -4.34 & -6.82 & -4.34 \\
\hline $65^{\circ} \mathrm{C}-95^{\circ} \mathrm{C}$ & -6.73 & -9.31 & -7.76 & -8.09 & -9.20 & -7.07 \\
\hline
\end{tabular}

It is worth noting that in Model A, the thermal elastic volumetric strain increment varies logarithmically with temperature (see equation (7)). As a consequence, coefficient $\alpha_{A}$ is necessarily dimensionless, contrary to $\alpha$ which has the dimension of the inverse of a temperature, as classically (see equation (6)). In this context, calling $\alpha_{A}$ a volumetric thermal expansion coefficient is misleading, but this was the choice originally made by the authors of [9].

In Model C, $\alpha$ is a material constant independent of effective stress $\left(p^{\prime}\right)$ and temperature $(T)$. The elastic volumetric strains are thus assumed to vary linearly with temperature. In Model A, however, $\alpha_{A}$ varies with the mean effective stress level as follows:

$$
\frac{d \alpha_{A}}{\alpha_{A}}=b \frac{d p^{\prime}}{p^{\prime}}
$$

where $b$ is a soil parameter describing the effect of mechanical stress.

In Model L, $\alpha$ increases with temperature and OCR values:

$$
\alpha=\left[\alpha_{0}+\zeta\left(T-T_{0}\right)\right] \frac{1}{d} \frac{p_{c 0}^{\prime}}{p^{\prime}}
$$

where $\alpha_{0}$ is the thermal expansion coefficient at a reference temperature $T_{0}$ and $\zeta$ is the slope of the variation of $\alpha$ with respect to temperature $T, p_{c 0}^{\prime}$ is the preconsolidation pressure at temperature $T_{0}$ and $d$ is a model parameter related to the shape of the yield surface in $\left(p^{\prime}, q\right)$ plane.

The volumetric thermal expansion coefficient $\alpha$ for natural Boom Clay was determined from TBoom9 test during the three cooling stages at different mean effective stresses using the volumetric strains estimated by the two methods previously introduced. The values obtained are given in Table II. For this test and in this particular range of temperature and OCR values, the changes of $\alpha$ with respect to temperature or stress are of the same order of magnitude. As a consequence, the general trends for the evolution of $\alpha$ with temperature and stress state (or OCR) are not completely clear. For instance, depending on the OCR value, $\alpha$ sometimes increases monotonically with temperature and sometimes not. Furthermore, depending on the method used to obtain the volumetric strains, the variations of $\alpha$ with temperature and strain can be different. It is thus difficult to corroborate the evolution predicted by Models A and L. It is thus recommended to adopt a constant thermal expansion coefficient as in Model C. Such a choice gives simple predictions without losing accuracy. This suggestion will be further supported when dealing with numerical simulations and elastoplastic theory.

The bulk modulus $K$ is the same as for the common Cam-Clay model in both Model C and Model A:

$$
K=\frac{v_{0} p^{\prime}}{\kappa}
$$

where $\kappa$ is the elastic slope in $\left(\ln p^{\prime}, v\right)$ space and $v_{0}$ is the initial specific volume. In Model L, a hypoelastic modulus is adopted:

$$
K=K_{\text {ref }}\left(\frac{p^{\prime}}{p_{\text {ref }}^{\prime}}\right)^{n^{e}}
$$

where $K_{r e f}$ is the bulk modulus at a reference effective mean pressure $p_{r e f}^{\prime}$, and $n^{e}$ is a soil parameter. 


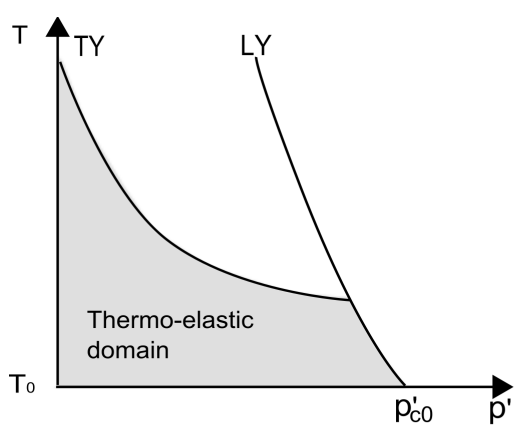

(a) Model C

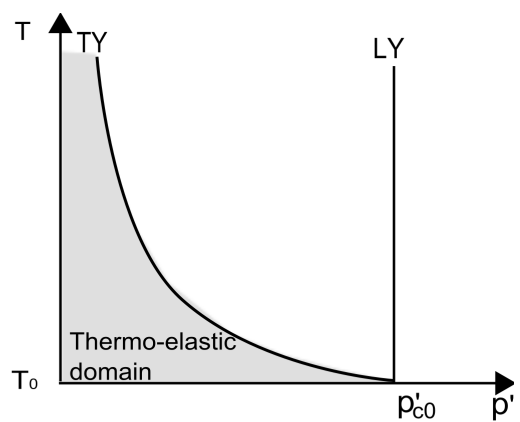

(b) Model A

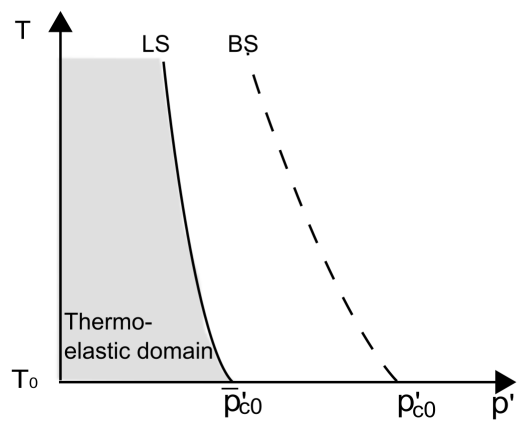

(c) Model L

Figure 3. Thermo-mechanic elastic domain in $\left(p^{\prime}, T\right)$ plane.

\subsection{Plastic behaviour}

3.2.1. Thermo-mechanical yield limit Figure 3 presents a schematic view of the thermo-mechanical elastic domain in $\left(p^{\prime}, T\right)$ plane for the three models. In both Models $\mathrm{C}$ and $\mathrm{A}$, the elastic zone is delimited by two yield curves: the conventional thermo-mechanical yield curve controlling the evolution of the preconsolidation pressure with temperature is denoted LY (loading yield limit), and the yield curve governing the thermal plastic behaviour is denoted TY (thermal yield limit).

The expressions of TY curves for Model C and Model A are given in Equation (12) and Equation (13), respectively:

$$
\begin{gathered}
p^{\prime}=-\frac{1}{\beta} \ln \left(\frac{T-T_{0}}{T_{c}-T_{0}}\right) \\
\frac{p_{c 0}^{\prime}}{p^{\prime}}=1+r^{T Y} \sqrt{\ln \left(\frac{T}{T_{0}}\right)}
\end{gathered}
$$

where $p_{c 0}^{\prime}$ is the preconsolidation pressure at the reference temperature $T_{0}, T_{c}$ is the temperature at which TY intersects the temperature axis in Model $\mathrm{C}$, and $\beta, r^{T Y}$ are shape parameters in Model $\mathrm{C}$ and Model A, respectively.

In Model $\mathrm{C}$, the preconsolidation pressure decreases with increasing temperature and the expression of LY reads:

$$
\frac{p^{\prime}}{p_{c 0}^{\prime}}=\exp \left(-r_{0}\left(T-T_{0}\right)\right)
$$

where $r_{0}$ governs the curvature of LY. A cooling phase is associated with an elastic unloading and the point representing the material's state in $\left(p^{\prime}, T\right)$ plane will not reach LY, which therefore will not be affected by any hardening process. In Model A, LY is defined with a different concept: the preconsolidation pressure will not be affected during a heating stage but will increase during a 
cooling stage according to an equation similar to that used in Model L:

$$
\frac{p^{\prime}}{p_{c 0}^{\prime}}=1-r^{L Y} \log _{10}\left(\frac{T}{T_{0}}\right)
$$

where $r^{L Y}$ is the model parameter that depends on the soil nature, $r^{L Y}$ is zero in the heating process and non-zero for the cooling process.

In Model L, the bounding surface concept is introduced. It can be seen from Figure 3 that a loading surface (denoted by LS) is defined so that it can deal with both normally consolidated and overconsolidated states. The conventional thermo-mechanical loading surface is taken as the bounding surface (denoted by BS). The bounding surface is defined in a similar approach as the LY of Model $\mathrm{C}$ without changes in the cooling phase:

$$
\frac{p^{\prime}}{p_{c 0}^{\prime}}=1-r_{T} \log _{10}\left(\frac{T}{T_{0}}\right)
$$

where $p_{c 0}^{\prime}$ is the mean effective stress on the bounding surface corresponding to $T_{0}, r_{T}$ governs the curvature of the yield surface. The expression of the loading surface is the same as the bounding surface:

$$
\frac{p^{\prime}}{r_{i s o} p_{c 0}^{\prime}}=1-r_{T} \log _{10}\left(\frac{T}{T_{0}}\right)
$$

with a scalar hardening parameter $r_{i s o}$ being defined as the ratio of the mean effective stress $\bar{p}_{c 0}^{\prime}$ on the loading surface at $T_{0}$ to $p_{c 0}^{\prime}$ on the bounding surface at $T_{0}$ :

$$
\frac{\bar{p}_{c 0}^{\prime}}{p_{c 0}^{\prime}}=r_{i s o}
$$

The value of $r_{i s o}$ is always smaller than or equal to 1 . For $r_{i s o}=1$, the loading and bounding surfaces coincide, and for $0 \leqslant r_{i s o}<1$, the loading surface is completely inscribed in the bounding surface.

3.2.2. Plastic mechanism Model $\mathrm{C}$ and Model A used two separate yield surfaces to describe the yielding behaviour in $p^{\prime}-T$ plane and correspondingly two plastic mechanisms are proposed. The plastic strains produced when increasing either the mean effective stress or the temperature and associated with the yielding of TY or LY curves are represented in Figure 4 (a)\&(b).

In Model $\mathrm{C}$, the volumetric plastic strain $d \varepsilon_{v}^{T, p}$ induced along thermal loading paths is different from that induced along mechanical loading paths, $d \varepsilon_{v}^{\sigma, p}$. The thermally induced plastic volumetric strain $d \varepsilon_{v 1}^{T, p}$ on TY or $d \varepsilon_{v 2}^{T, p}$ on LY associated with changes in temperature at constant effective stress can be determined according to the following equation:

$$
d \varepsilon_{v i}^{T, p}=\alpha_{p}\left[\exp \left(\alpha_{p}\left(T-T_{0}\right)\right)-a\right] d T \quad \text { with } i \in\{1,2\}
$$

where $\alpha_{p}$ and $a$ are parameters describing the variation of $d \varepsilon_{v}^{T, p}$ with respect to a temperature increment $d T$. To describe OCR effects on $d \varepsilon_{v}^{T, p}, \alpha_{p}$ is taken as dependent on the value of OCR. For normally consolidated states (on LY), $\alpha_{p}$ is constant and given by:

$$
\alpha_{p}=-\frac{\alpha}{1-a}
$$

For overconsolidated soils (on TY), $\alpha_{p}$ decreases with OCR increases, as follows:

$$
\alpha_{p}=-\frac{\alpha}{\exp \left(\frac{1}{c_{2}} \ln \left(\frac{1}{c_{1}} \frac{p^{\prime}}{p^{\prime}{ }_{c 0}}\right)\right)-a}
$$

where $c_{1}$ and $c_{2}$ are parameters that can be determined from the transition point between expansion and contraction of the total volume change associated with temperature changes. $d \varepsilon_{v 1}^{\sigma, p}$, induced 

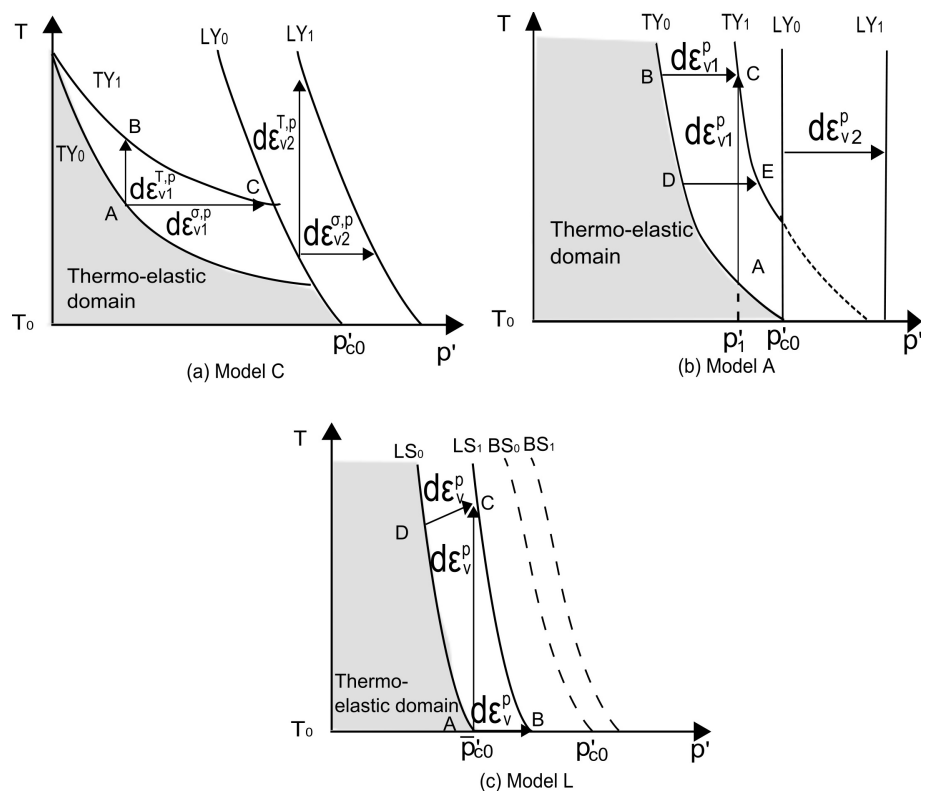

Figure 4. Evolution of yield surface under thermo-mechanical loading in $p^{\prime}-T$ plane.

along mechanical loading paths on TY, is expressed as follows:

$$
d \varepsilon_{v 1}^{\sigma, p}=\frac{\alpha_{1}}{v_{0}} \frac{d p^{\prime}}{p^{\prime}}
$$

where $\alpha_{1}$ is the slope of the inelastic part in $\left(\ln p^{\prime}, v\right)$ space in the overconsolidated state. $d \varepsilon_{v 2}^{\sigma, p}$, obtained along mechanical loading paths on LY, has the following expression as in the common Cam Clay Model:

$$
d \varepsilon_{v 2}^{\sigma, p}=\frac{\lambda-\kappa}{v_{0}} \frac{d p^{\prime}}{p^{\prime}}
$$

where $\lambda$ is the normal-consolidation slope in $\left(\ln p^{\prime}, v\right)$ space.

$p_{c 0}^{\prime}$ and $\beta$ appearing in the definition of TY and LY in Model $\mathrm{C}$ are hardening variables that control the evolution of TY and LY respectively. The hardening laws read:

$$
d \beta=\frac{-\exp \left(\beta p^{\prime}\right)}{p^{\prime}\left(T_{c}-T_{0}\right) \alpha_{p}\left[\exp \left(\alpha_{p}\left(T-T_{0}\right)\right)-a\right]} d \varepsilon_{v 1}^{T, p}-\frac{\beta}{\alpha_{1}} d \varepsilon_{v 1}^{\sigma, p}
$$

and

$$
\begin{aligned}
& d p^{\prime}{ }_{c 0}=\left\{\frac{r_{0}}{\alpha_{p}\left[\exp \left(\alpha_{p}\left(T-T_{0}\right)\right)-a\right]} d \varepsilon_{v 2}^{T, p}+\left(\frac{v_{0}}{\lambda-\kappa}\right)\left(d \varepsilon_{v 2}^{\sigma, p}+d \varepsilon_{v 1}^{\sigma, p}\right)\right. \\
& \left.+\left(\frac{k v_{0}}{\alpha_{p}\left[\exp \left(\alpha_{p}\left(T-T_{0}\right)\right)-a\right]}\right) d \varepsilon_{v 1}^{T, p}\right\} p^{\prime}{ }_{c 0}
\end{aligned}
$$

where $k$ is a positive parameter that describes the coupling effects between TY and LY. These hardening laws provide a one-way coupling between TY and LY plastic mechanisms in the sense that LY moves when TY is activated, but not reciprocally. This behaviour is observed experimentally [18].

Model A defines a theoretical mechanism to interpret the plastic strain induced along a thermal loading path. As shown in Figure 4(b), during heating at $p_{1}^{\prime}$ (path A-C), the hardening effective stress $p^{\prime}$ on TY decreases with temperature increase according to Equation 13 and the plastic strain is generated once the hardening effective stress $p^{\prime}$ reaches $p_{1}^{\prime}$. The volumetric plastic strain increment $d \varepsilon_{v}^{p}$, along the thermal loading path at a constant mean effective stress (path A-C) is assumed to be 
identical to that generated along the mechanical loading path (path B-C ). When TY is reached, the volumetric plastic strain $d \varepsilon_{v 1}^{p}$, along mechanical and (or) thermal load paths can be determined:

$$
d \varepsilon_{v 1}^{p}=\frac{\omega_{T}}{v_{0}} \frac{d p^{\prime}}{p^{\prime}}
$$

where $\omega_{T}$ is the plastic modulus at temperature $T$, a function of $r^{T Y}, r^{L Y}$ and temperature $T$,

$$
\omega_{T}=(\lambda-\kappa) \frac{-\ln \left(1-r^{L Y} \log _{10}\left(T / T_{0}\right)\right)}{\ln \left(r^{T Y} \ln \left(T / T_{0}\right)+1\right)}
$$

The plastic volumetric strain $d \varepsilon_{v 2}^{p}$, associated to LY, can be generated only along mechanical loading paths when the applied stress exceeds LY and can be determined by:

$$
d \varepsilon_{v 2}^{p}=\frac{\lambda-\kappa-\omega_{T}}{v_{0}} \frac{d p^{\prime}}{p^{\prime}}
$$

For TY, no explicit hardening law is given. The evolution of LY is controlled by the hardening parameters $p_{c 0}^{\prime}$. It depends on the plastic volumetric strain increment $d \varepsilon_{v 2}^{p}$ :

$$
d p_{c 0}^{\prime}=\frac{v_{0}}{\lambda-\kappa-\omega_{T}} p_{c 0}^{\prime} d \varepsilon_{v 2}^{p}
$$

In Model L, the volumetric plastic strains $d \varepsilon_{v}^{p}$ along thermal loading paths and mechanical loading paths are produced by the same mechanism of plastic hardening of $\bar{p}_{c 0}^{\prime}$ as shown in Figure 4(c). These two loading paths are coupled and a common hardening law is provided for effective stress and temperature increases. The volumetric plastic strain between $\mathrm{LY}_{0}$ and $\mathrm{LY}_{1}$ is independent of the loading path.

During loading, the scalar variable $r_{i s o}$ represents the progressive plastification in relation to the plastic volumetric strain and controls the ratio between the sizes of loading surface and bounding surface. The following law is adopted:

$$
d r_{i s o}=\frac{\left(1-r_{i s o}\right)^{2}}{c} d \varepsilon_{v}^{p}
$$

where $c$ is a soil parameter.

During an unloading-reloading cycle, $r_{\text {iso }}$ decreases to follow the decrease of the effective mean pressure $p^{\prime}$ in the unloading process and will be adjusted in a sudden fashion with a new value of $r_{i s o}$ at the moment of change in loading direction (unloading-reloading):

$$
r_{i s o}=r_{i s o}^{e}+\frac{p^{\prime}{ }_{c y c}}{p^{\prime}{ }_{c 0}}
$$

where $r_{i s o}^{e}$ represents the size of the purely elastic nuclei, $p_{c y c}^{\prime}$ is the mean effective stress at the last change in loading direction (unloading-reloading). The widely used hardening law based on the relationship between the preconsolidation pressure, $p_{c 0}^{\prime}$, and the volumetric plastic strain, $\varepsilon_{v}^{p}$, in $\left(\ln p^{\prime}, v\right)$ plane is given by:

$$
d p_{c 0}^{\prime}=h p_{c 0}^{\prime} d \varepsilon_{v}^{p}
$$

where $h p_{c 0}^{\prime}$ is the plastic modulus.

\section{NUMERICAL SIMULATIONS}

The performance of the thermo-mechanical models presented above is investigated. Natural Boom Clay is considered and the predicted results are compared to the experimental results. To evaluate the capability of models in predicting the thermally induced volume change following different loading 
Table III. Input parameters for the simulations of natural Boom Clay behaviour

\begin{tabular}{|c|c|c|c|}
\hline & Model C & Model A & Model L \\
\hline Elastic part & $\begin{array}{l}\alpha=-5.1 \times 10^{-5^{\circ}} \mathrm{C}^{-1} \\
-- \\
\kappa=0.046 \\
--\end{array}$ & $\begin{array}{l}\alpha_{\text {ref }}{ }^{*}=-1.11 \times 10^{-2} \\
b=0.31 \\
\kappa=0.046 \\
--\end{array}$ & $\begin{array}{l}\alpha=-1.3 \times 10^{-5^{\circ}} \mathrm{C}^{-1} \\
-- \\
K_{r e f}=130 \mathrm{MPa} \\
n^{e}=0.4\end{array}$ \\
\hline Yield limits & 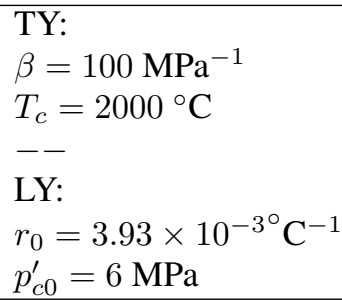 & $\begin{array}{l}\text { TY: } \\
r_{T Y}=1.56 \\
p_{c 0}^{\prime}=6 \mathrm{MPa} \\
-- \\
\mathrm{LY}: \\
r_{L Y}=0.31 \\
--\end{array}$ & $\begin{array}{l}\text { Loading surface: } \\
r_{T}=0.55 \\
p_{c 0}^{\prime}=6 \mathrm{MPa} \\
r_{i s o}^{e}=0.001 \\
\text { Bounding surface: } \\
-- \\
--\end{array}$ \\
\hline Plastic strain & $\begin{array}{l}\text { TY: } \\
a=0.982 \\
\alpha_{1}=2.51 \times 10^{-4} \\
c_{1}=0.5833 \\
c_{2}=-0.019^{\circ} \mathrm{C}^{-1} \\
\text { LY: } \\
\lambda=0.178\end{array}$ & $\begin{array}{l}\text { TY: } \\
\lambda=0.178 \\
-- \\
-- \\
-- \\
\text { LY: } \\
--\end{array}$ & $\begin{array}{l}-- \\
-- \\
-- \\
-- \\
--\end{array}$ \\
\hline Hardening laws & $\begin{array}{l}\text { TY: } \\
-- \\
\text { LY: } \\
k=0.012\end{array}$ & $\begin{array}{l}\text { TY: } \\
-- \\
\text { LY: } \\
--\end{array}$ & $\begin{array}{l}c=0.012 \\
h=18\end{array}$ \\
\hline
\end{tabular}

${ }^{*}$ Thermal expansion coefficient at $0.1 \mathrm{MPa}$.

paths and the thermally induced hardening effect (two key features of the thermo-mechanical behaviour of saturated clays), two sets of tests with combined thermo-mechanical loadings are simulated. Note that because of the lack of relevant data about natural Boom Clay (data obtained from experiments on samples saturated under the in-situ stress are exclusively considered in this work), set 2 is purely numerical.

In set 1 , two cases are simulated. The first case (Simulation 1) corresponds to TBoom9 test on a single soil specimen with the loading path shown in Figure 1. The second case (Simulation 2) corresponds to the same experimental path but with three different natural specimens (one per thermal cycle). The three specimens are first saturated at $p^{\prime}=2 \mathrm{MPa}$ and loaded up to $p^{\prime}=6 \mathrm{MPa}$. After that, two samples are unloaded to $3 \mathrm{MPa}$ and $1 \mathrm{MPa}$, respectively. Doing so, three specimens with three distinct overconsolidation ratios are obtained. From these consolidation pressures, a particular heating-cooling cycle $\left(21.5^{\circ} \mathrm{C}-95^{\circ} \mathrm{C}-21.5^{\circ}\right)$ is applied on each specimen.

Table III shows the input parameters of the three models. Note that all the parameters can be calibrated from the experimental results and the values are proposed by the authors in their respective original papers [3, 4, 9]. It can be observed that Model A and Model L require less parameters for the plastic strains prediction since the plastic strains induced along the mechanical loading path and the thermal loading path are coupled. It should be mentioned that although Model L considers the effect of temperature and effective stress on the thermal expansion coefficient (see Equation 9), a constant thermal expansion coefficient (see Table III) was adopted in their simulation. Moreover, in the original work of parameters calibration, the experimental results determined using Method 1 (thermal isotropic strains) were used for Model A and Model L, whereas experimental results determined using Method 2 (thermal anisotropic strains) were used for Model C.

As seen in Section 3, depending on the model, a logarithmic or a power function is chosen for the thermo-mechanical yield limit for $T=T_{0}$. Figure 5 compares the size of the thermo-mechanical elastic zone predicted by the three models at $p^{\prime}=2 \mathrm{MPa}$ and $T=21.5^{\circ} \mathrm{C}$ (point A in Figure 1). It can be observed that the thermo-mechanical elastic zone (being delimited by $\mathrm{TY}_{C}$ and $\mathrm{LY}_{C}$ ) 


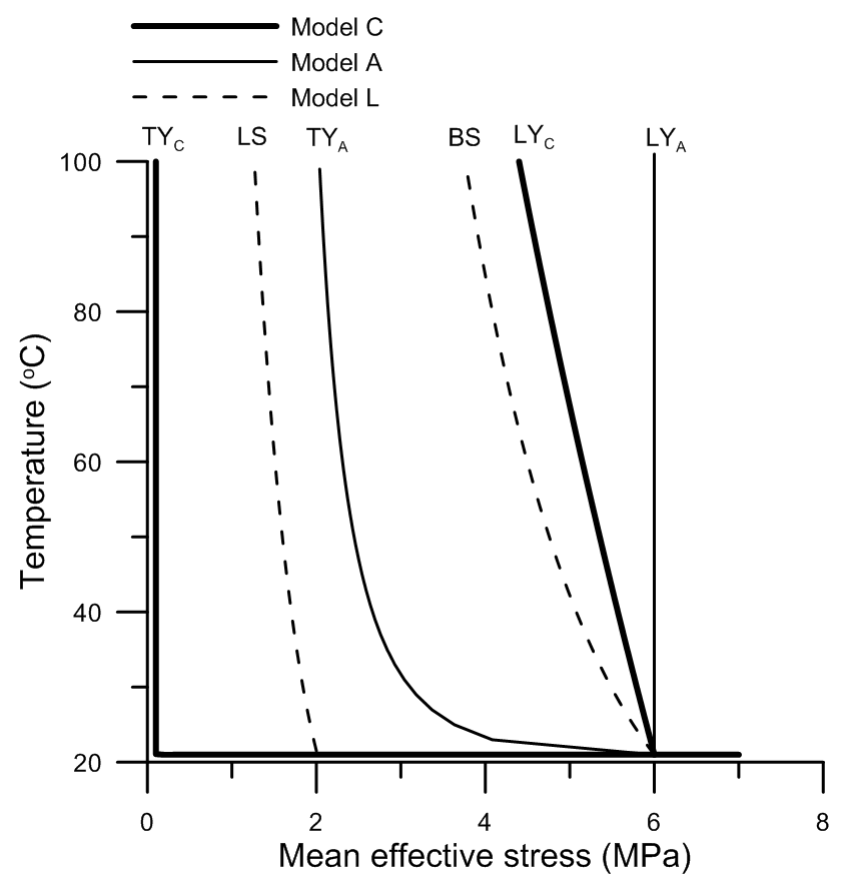

Figure 5. Thermo-mechanical yield limits (TY and LY).

adopted in Model $\mathrm{C}$ is the smallest and the one in Model A (being delimited by $\mathrm{TY}_{A}$ and $\mathrm{LY}_{A}$ ) is the largest.

Figure 6 compares the volumetric strain predictions in case of Simulation 1 with the experimental results. It shows that all the three proposed models give similar results and can capture the essential features of the thermo-mechanical behaviour. However, none of them can describe the expansive irreversible isotropic volumetric strain (calculated using Method 1) at $p^{\prime}=1 \mathrm{MPa}$, generated after a heating-cooling cycle. Note that this behaviour was also observed on other soils such as the Bangkok soft clay as reported by Abuel-Naga et al. [9].

Figure 7 compares the volumetric strain predictions in case of Simulation 1 and Simulation 2. It can be observed that Simulation 1 and Simulation 2 give different predictions for all the three models, and Model L give the largest difference because of its high sensitivity to the loading history. Taking $p^{\prime}=6 \mathrm{MPa}$ at $T=21.5^{\circ} \mathrm{C}$ (point I in Figure 1) for Model $\mathrm{L}$ for instance, the yield limits can be determined by considering their evolution according to the loading history. Even though the previously applied loading path is located inside the Bounding surface, plastic strains are generated due to the activation of the Loading surface. The preconsolidation pressure thus increases. Because of the different loading histories in Simulation 1 and in Simulation 2, different preconsolidation pressures (being 10.5 MPa and $8.7 \mathrm{MPa}$, respectively) are obtained at point I, resulting in different predictions for the subsequent heating-cooling path (path I-J-K in Figure 1).

In set 2 (Simulation 3), the soil specimen is first saturated at $p^{\prime}=2 \mathrm{MPa}$ and loaded up to 8 $\mathrm{MPa}$ (point $\mathrm{B}$ in Figure 8), giving a normal consolidated state. Afterwards, a heating-cooling cycle of $21.5^{\circ} \mathrm{C}-95^{\circ} \mathrm{C}-21.5^{\circ} \mathrm{C}$ (path $\mathrm{B}-\mathrm{C}-\mathrm{D}$ ) is applied under this consolidation pressure followed by a mechanical re-loading up to $20 \mathrm{MPa}$ (path D-E).

Figure 9 compares the results for Simulation 3 as predicted by the three models which provide similar results. During the isotropic loading up to $8 \mathrm{MPa}$ at $21.5^{\circ} \mathrm{C}$, the sample behaves elastically and then elasto-plastically. The classic bilinear compression behaviour is predicted by Model $\mathrm{C}$ and Model $\mathrm{A}$ in $\varepsilon_{v}-\log p^{\prime}$ space since MCC is adopted in the isothermal condition, but the soil behaviour by Model L is smoother due to the contribution of the bounding surface plasticity concept, as shown in Figure 9 (A-B). 

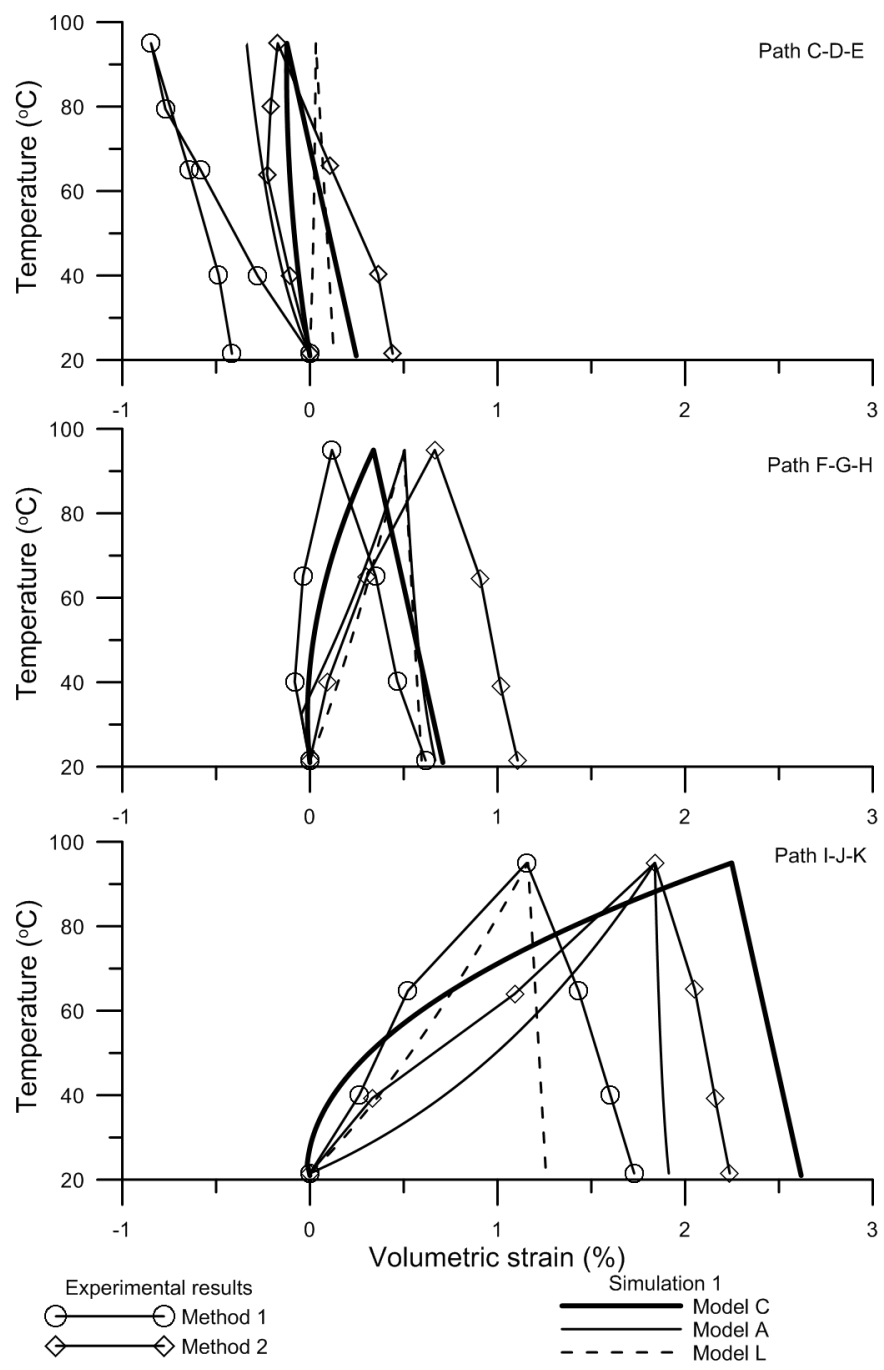

Figure 6. Comparison between observed and predicted thermally induced volumetric strain in Simulation 1.

During the heating process (B-C), in Model C, TY curve is activated, and the TY-LY coupling also moves LY forward. At the end of the heating stage (point C), a value of $11.1 \mathrm{MPa}$ for $p_{c 0}^{\prime}$ can be obtained using Equations 24 and 25. The cooling stage (C-D) does not produce any plastic strain, thus keeping $p_{c 0}^{\prime}$ constant. In Model A, the preconsolidation pressure is kept constant ( $8 \mathrm{MPa}$ ) in the heating phase and increases during the cooling phase. A final value of $10.0 \mathrm{MPa}$ at point $\mathrm{D}$ is predicted for $p_{c 0}^{\prime}$ using Equation 15. In Model L, LS mechanism is activated and moves forward together with BS surface during the heating phase. During the cooling-reloading process, the size of LS defined by $r_{i s o}$ is reinitialised according to Equation 31 and a small elastic nucleus is assumed at the beginning of the reloading process. For the three models, the soil response is first elastic and then elastoplastic during the reloading process, predicting the slightly overconsolidated behaviour when a mechanical loading is performed after a thermal cycle in normally consolidated state. Even though no direct comparison with experimental results is made here for the reasons mentioned above, it can be seen that the three models can satisfactorily capture the thermal hardening phenomenon as observed in [13] for instance. 

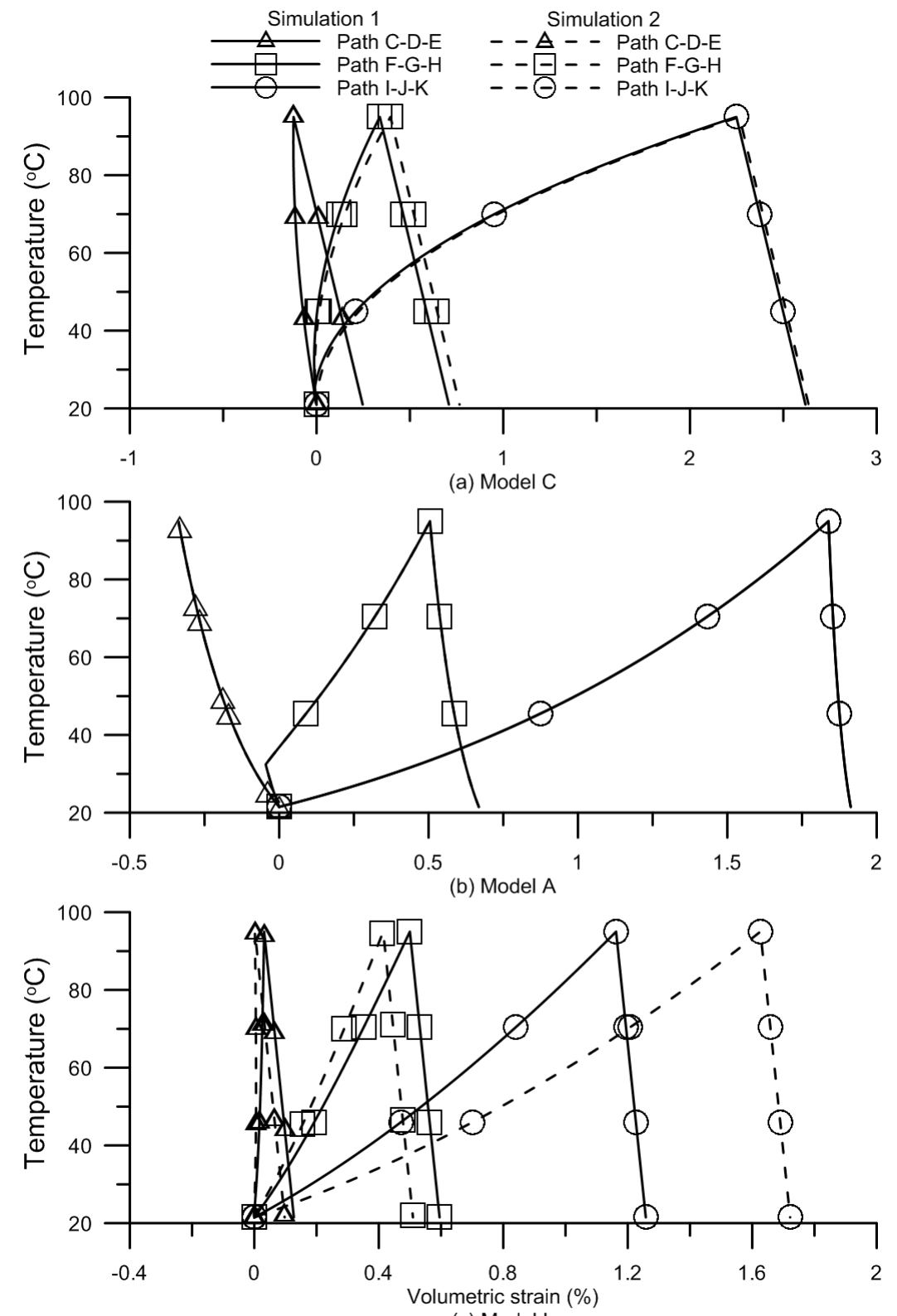

(c) Model L

Figure 7. Comparison between Simulation 1 and Simulation 2 by the three models: (a) Model C, (b) Model A, (c) Model L.

\section{DISCUSSION}

The numerical simulations in the previous section have shown the capability of the constitutive models to catch the main experimental evidences. The constitutive models are now discussed in terms of elasto-plastic theory and thermodynamic theory.

The thermo-elastic behaviour is one of the most fundamental issues in the thermo-mechanical constitutive model. Examination of the three models investigated shows that the elastic strain in Model A and Model L is loading-path dependent whereas the elastic strain in Model C is loadingpath independent. To illustrate this point, the volumetric strain along path A-B-D and path A-C-D in Figure 10 is analysed. For Model L, the volumetric strain along path B-D is equal to that along path 


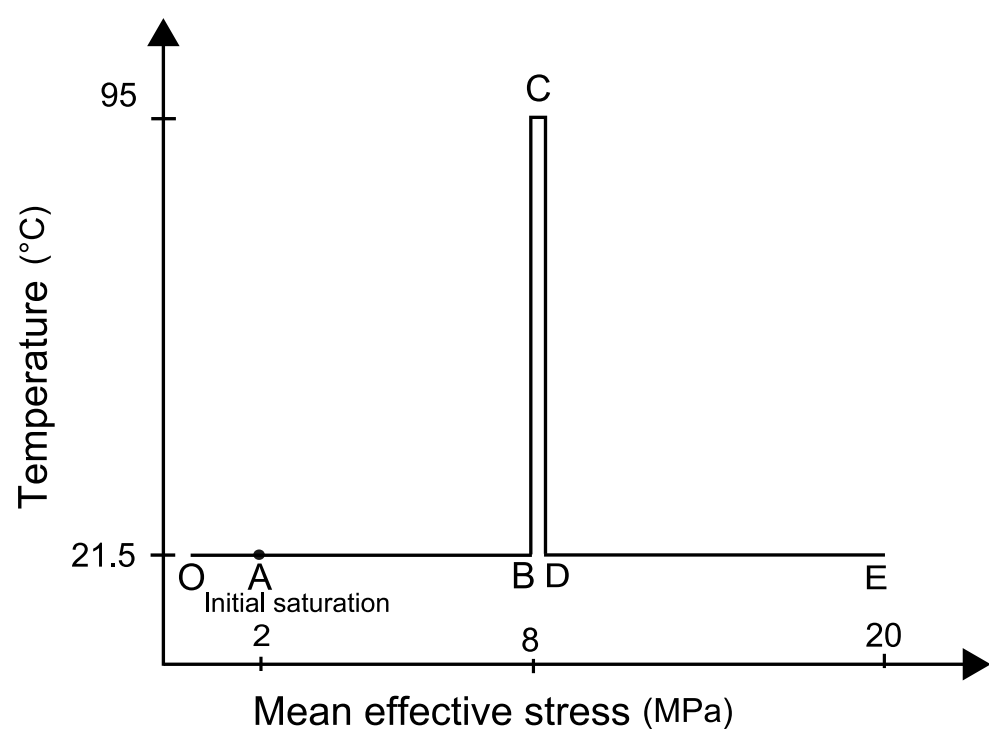

Figure 8. Isotropic thermo-mechanical loading path of Simulation 3.

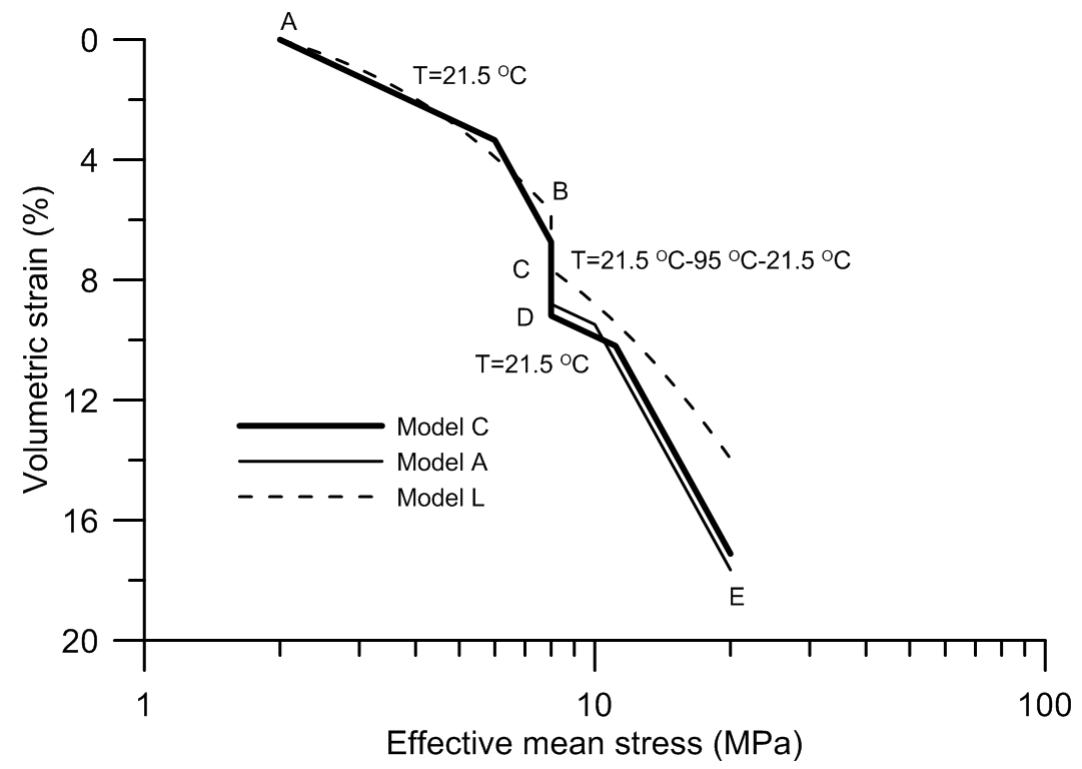

Figure 9. Predicted response of the soil in Simulation 3.

A-C since the elastic modulus $\mathrm{K}$ is independent of temperature. However, according to Equation 9, the volumetric strain along path A-B is different from that along path C-D since the thermal expansion coefficient changes between these two paths characterised by two distinct mean effective stresses. Thus, the total volumetric strains along path A-B-D and A-C-D are not identical even if the loading path is inside the thermo-elastic zone. In other words, the elastic strain increment depends on the order of application of temperature and effective stress changes:

$$
\frac{\partial^{2} \varepsilon_{v}^{e}}{\partial p^{\prime} \partial T} \neq \frac{\partial^{2} \varepsilon_{v}^{e}}{\partial T \partial p^{\prime}}
$$

Such an un-closed loop traduces the loading-path dependency of the elastic behaviour which poses some problems when developing a constitutive model in the framework of the elasto-plasticity 


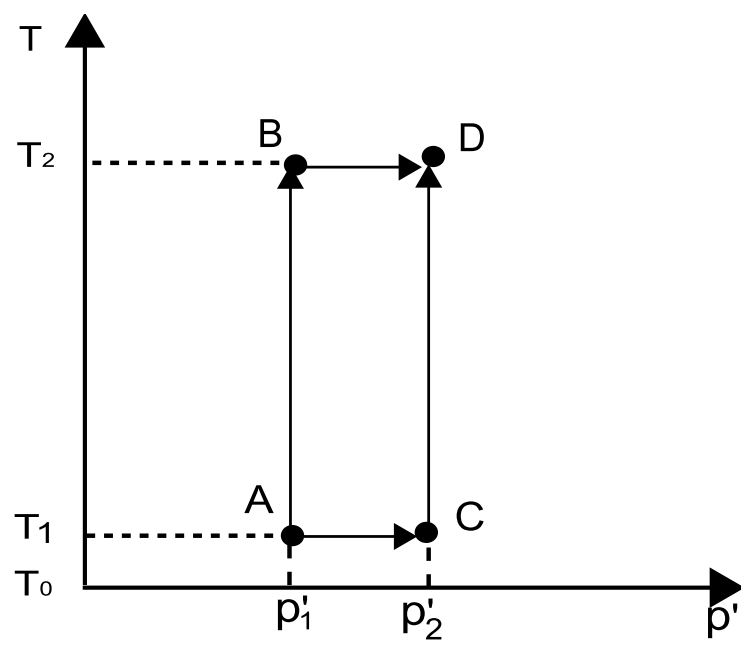

Figure 10. Loading path in the effective stress and temperature space.

theory. Model A defines a similar loading-path dependent elastic behaviour as Model L, whereas Model C defines an identical volumetric strain along path A-B-D and A-C-D, with no loading-path dependency of the elastic behaviour.

The thermo-mechanical elastic zones defined by all the three models have a common and salient change in comparison with the early models. In the early models (e.g. [5, 6]), the thermomechanical elastic zone is defined by a conventional yield surface accounting for thermal evolution of the preconsolidation pressure. Inside this zone, purely elastic strain is generated. The parameter governing the thermo-elastic behavior (that is the thermal expansion coefficient) is thereby always determined along heating tests lying inside the conventional yield surface. However, the three models studied in this paper assume that thermally induced plastic strain would occur during such heating stages even when the stress state of soil is inside the conventional yield surface. To be consistent with this new thermo-elasto-plastic framework, specimens with different OCR values should be subjected to heating-cooling cycles and the thermal-elastic behavior should be characterised from the cooling stages instead of the heating stages.

As seen in Section 3, different plastic strain variables are chosen by the three models. In Model C, the volumetric plastic strain generated during thermo-mechanical hardening is split into two parts: $d \varepsilon_{v}^{\sigma, p}$ along a mechanical loading path at an given temperature and $d \varepsilon_{v}^{T, p}$ along a thermal loading path at a constant effective stress. This conveniently describes the thermo-mechanical behaviour and thus gives a hardening law depending on the loading path. As seen in Figure 4(a), the loading paths $\mathrm{AB}$ and $\mathrm{AC}$ result in the same change of the yield surface from $\mathrm{TY}_{0}$ to $\mathrm{TY}_{1}$. However, these two paths give rise to different volumetric plastic strains. Furthermore, as seen in Table III, distinct parameters are required to predict the plastic strain generated along thermal loading paths and mechanical loading paths. This induces a higher number of parameters to be identified and thus increases the complexity of the model. Also, it should be noted that although the volumetric plastic strain $\varepsilon_{v}^{T, p}$ is induced by temperature changes, this variable is not thermodynamically conjugated to temperature.

In the concept of Model A, there is no distinction between thermo-mechanical plastic strains induced by either thermal or mechanical loadings. However, distinct flow rules are adopted for each yield surface (TY or LY). And the plastic strain increment when TY is activated $d \varepsilon_{v 1}^{p}$ is loading path dependent since the plastic modulus $\omega_{T}$ depends on temperature. For instance, mechanical loading paths BC and DE (see Figure 4(b)) will produce different plastic volumetric strains.

In Model L, the plastic volumetric deformation induced by the different loading paths (Figure 4(c)) is calculated according to a single flow rule. It can be determined by the change in size of the yield surface from $\mathrm{LS}_{0}$ to $\mathrm{LS}_{1}$, irrespective of loading paths. 


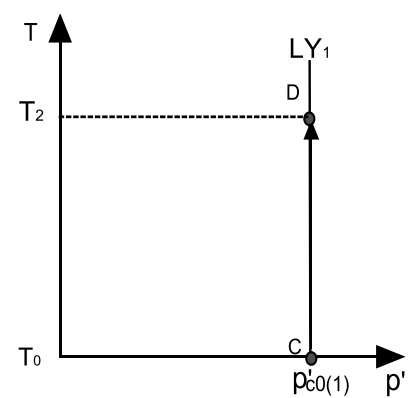

(a) Heating action

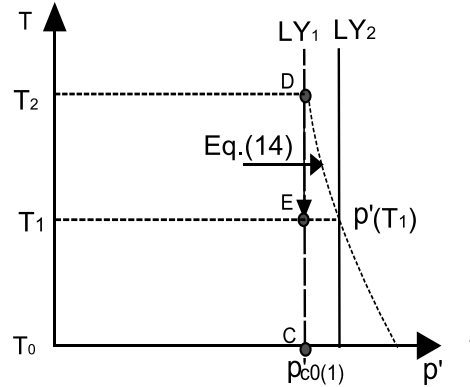

(b) Cooling action at $T_{1}$

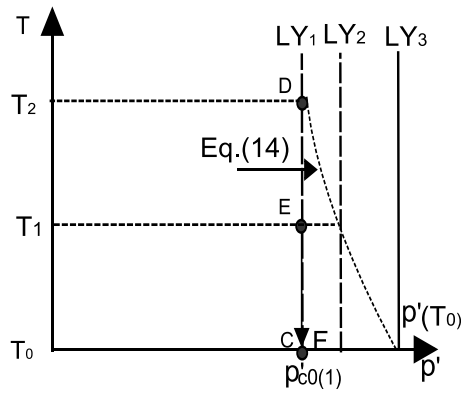

(c) Cooling action at $\mathrm{T}_{0}$

Figure 11. Evolution of LY curve in a heating-cooling cycle in Model A.

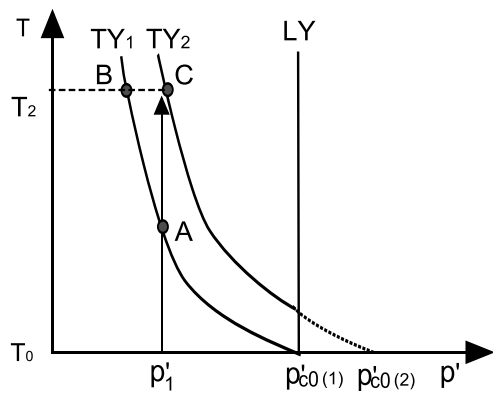

Figure 12. Evolution of TY curve in heating process in Model A.

From the simulation results presented in Section 4, Model A is able to predict the plastic strain induced along a thermal loading path in both normally consolidated and overconsolidated conditions thanks to the introduction of an additional plastic mechanism in the effective stress-temperature space, namely TY. However, the two plastic mechanisms associated with yield surfaces TY and LY are not discussed in the light of the classic elasto-plastic theory. The evolution of LY during a heating-cooling cycle is firstly studied. As presented earlier, in Model A, the thermal evolution of the preconsolidation pressure follows a concept different from the other two models. Figure 11 shows the evolution of LY during a heating-cooling cycle. During heating from $\mathrm{T}_{0}$ to $\mathrm{T}_{2}$ (C to $\mathrm{D}$ in Figure 11(a)) of a normally consolidated specimen, the preconsolidation pressure is temperature independent, and $\mathrm{LY}_{1}$ during this process thus keeps constant, as illustrated in Figure 11(a). Under the subsequent cooling process from $T_{2}$ back to $T_{1}$ and then to $T_{0}$ (D-E-F), as seen in Figure $11(b) \&(c)$, the preconsolidation pressure increases. Its value at temperatures $T_{1}$ and $T_{2}$ can be determined using Equation 15. LY thus evolves from $\mathrm{LY}_{1}$ to $\mathrm{LY}_{2}$ and then $\mathrm{LY}_{3}$ during the cooling process. It should be noted that according to Model A the preconsolidation pressure increase and the corresponding evolution of the yield surface are even adopted during a purely elastic process. This is not consistent with the conventional elasto-plastic theory stating that the preconsolidation pressure is increased and the yield surface evolves with the plastic strain increment, and that they keep unchanged in a purely elastic process [19]. As for TY, Figure 12 shows its evolution in a heating process from $\mathrm{T}_{0}$ to $\mathrm{T}_{2}$ at effective stress point $p_{1}^{\prime}$, which corresponds to a lightly overconsolidated state at room temperature. During a heating phase A-C, TY evolves from $\mathrm{TY}_{1}$ to $\mathrm{TY}_{2}$ according to Equation 13. To maintain TY at stress point $p_{1}^{\prime}$, the value of $p_{c 0}^{\prime}$ would change from $p_{c 0(1)}^{\prime}$ to $p_{c 0(2)}^{\prime}$. However, LY will keep unchanged and $p_{c 0}^{\prime}$ will remain constant (still equal to $p_{c 0(1)}^{\prime}$ ) in a heating process as described above. This point shows the inconsistency between TY and LY plastic mechanisms.

In Model L, the bounding surface theory is introduced and a single plastic mechanism is adopted to simulate the thermo-plastic behavior in both overconsolidated and normally consolidated states. 

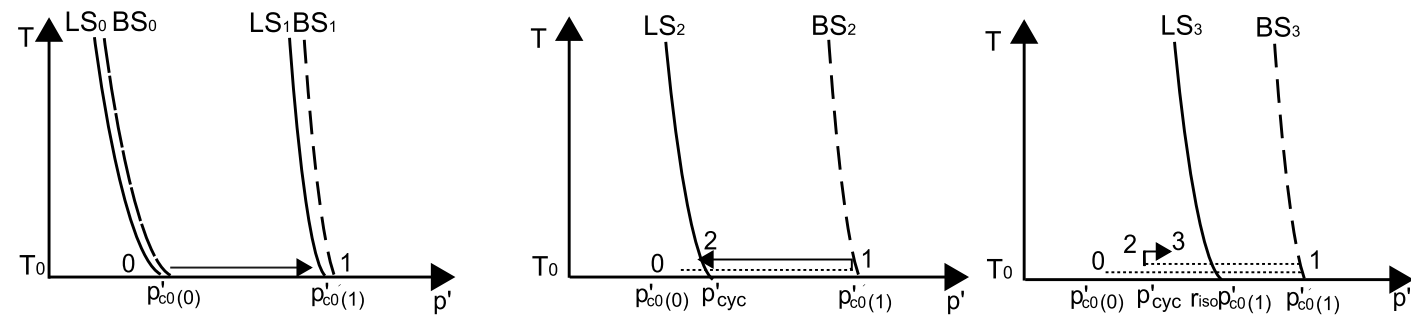

Figure 13. Plastic mechanism over a mechanical isotropic loading-unloading-reloading cycle in Model L.

To this aim, the loading surface expands and shrinks according to the evolution of $r_{\text {iso }}$ during a loading-unloading-reloading cycle. Model L appears as more simple than the two others, with a single plastic mechanism in $\left(p^{\prime}, T\right)$ space. This constitutive model can thus be implemented into a numerical code more easily than Model C and Model A which both include two plastic mechanisms. In the following part, the evolution mechanism of the loading surface is discussed.

As an illustration, Figure 13 schematically presents the evolution of the yield limit in a loadingunloading-reloading process. During the first loading (path 0-1), loading surface (LS) and bounding surface (BS) coincide when $r_{i s o}=1$. The preconsolidation pressure at $T_{0}$ evolves from $p_{c 0(0)}^{\prime}$ to $p_{c 0(1)}^{\prime}$ with the plastic strain evolving from $\varepsilon_{v 0}^{p}$ to $\varepsilon_{v 1}^{p}$. During the subsequent unloading process (path 1-2), no plastic strain is generated and thus BS keeps constant. However, the model assumes that LS will move back to follow the decrease of the mean effective pressure $p^{\prime}$. At the start of the reloading process (path 2-3), the size of LS will be adjusted suddenly from $\mathrm{LS}_{2}$ to $\mathrm{LS}_{3}$ with a new $r_{i s o}$ according to Equation $31\left(r_{i s o}=r_{i s o}^{e}+\frac{p^{\prime}{ }_{c y c}}{p^{\prime}{ }_{c 0(1)}} ; \epsilon_{v}^{p}=\epsilon_{v 1}^{p}\right.$ remains constant). This peculiar behaviour is possible because LS is treated as a "loading surface" in the sense of the bounding surface plasticity concept introduced by Dafalias et al. $[20,21]$ (where the loading function $f$ is always null) and not as a yield surface that could be either activated or not, in the sense of classic elastoplasticity (where the yield criterion $f$ may be negative). However, a difference appears between the treatment of the LS locus and the original concept from Dafalias. It concerns the fact that the stress point does not pertain to the LS surface at any time. This is the case when the loading direction is changed within the elastic nucleus (from unloading to loading, see for instance Figure 13). At this point, the size of the LS locus is "adjusted" to coincide with the elastic nucleus (and thus $f_{L S}$ becomes negative) whereas according to Dafalias et al., this locus should remain attached to the stress point (and thus $f_{L S}=0$ at any time). In this latter case, plastic strains are cancelled within the elastic nucleus by imposing an infinite plastic modulus. Apart from this different treatment of stress paths within the elastic nucleus, Model L provides simulations that would be similar to those obtained using strictly Dafalias et al. concept.

\section{CONCLUSIONS}

Several advanced thermo-mechanical models as Cui et al. [3], Abuel-Naga et al. [9] and Laloui and François $[4,10]$ have been proposed recently and most of them are based on the experimental test carried out by Baldi et al.[1] on natural Boom Clay. It is however observed that the experimental results obtained by Baldi et al. were not correctly accounted for in these models. Moreover, these models present some similarities and also some differences in different aspects. It appears then necessary to clarify the test by Baldi et al. and to make a comparison of the models.

For this purpose, the experimental test (TBoom9) conducted on natural Boom Clay by Baldi et al. was presented with special attention on the successive thermal mechanical loading path and the drained thermal volumetric strain results. A discussion on the methods to obtain volumetric strain was made. It has been shown that there are two distinct series of experimental data depending on the method adopted, the difference between them being significant. Obviously, this difference can have 
significant impact on the development of constitutive models which are based on one or another data series.

The assessment of the isotropic part of the models of Cui et al. [3] - Model C, Abuel-Naga et al. [9] - Model A, Laloui and François [4, 10] - Model L showed that each model has its advantages and drawbacks. The main conclusions are as follows:

- Although the three models are elaborated with different concepts with respect to elastic behaviour and plastic mechanism(s), all of them can capture the main features of the thermomechanical isotropic behaviour of saturated clays.

- One of the main differences on thermo-elastic equations amongst the three models is the choice made for the evolution of the thermal expansion coefficient with temperature and stress: only Model C considers a constant value. The assessment performed showed that taking a constant value permits to remain simple and relatively accurate in describing the thermoelastic behaviour as well as to ensure that the elastic behavior is loading-path independent.

- In both Model C and Model A, two yield surfaces are introduced to describe the thermomechanical plastic behavior. Correspondingly, two plastic mechanisms were proposed. Model L uses the bounding surface theory and a single plastic mechanism is used. Thus, Model L can be implemented more easily into a numerical code.

- The plastic strain variables along a mechanical loading path and a thermal loading path are distinct and defined for each plastic mechanism without coupling in Model C. In Model A, the thermal plastic strain is not differentiated from the mechanical one and a single plastic strain variable is used for all the plastic mechanisms. Model L couples stress and temperatureinduced hardening process and a unique plastic strain along different loading paths is defined.

\section{ACKNOWLEDGEMENT}

The authors would like to thank Dr. Bertrand François and Dr. Hossam Abuel-Naga for their patient answers and interesting discussions about their thermo-mechanical models.

\section{REFERENCES}

1. Baldi G, Hueckel T, Peano A, Pellegrini R. Developments in modelling of thermo-hydro-geomechanical behaviour of boom clay and clay-based buffer materials. Commission of the European Communities, Nuclear Science and Technology 1991; :EUR 13 365/1 and EUR 13 365/2.

2. Seneviratne H, Carter J, Airey D, Booker J. Review of models for predicting the thermomechanical behaviour of soft clays. International Journal for Numerical and Analytical Methods in Geomechanics 1993; 17(10):715 - 733.

3. Cui Y, Sultan N, Delage P. A thermomechanical model for saturated clays. Canadian Geotechnical Journal 2000; 37(3):607-620.

4. François B. Thermo-plasticity of fine-grained soils at various saturation states: Application to nuclear waste disposal. PHD 2008; .

5. Hueckel T, Baldi G. Thermoplasticity of saturated clays. experimental constitutive study. Journal of geotechnical engineering 1990; 116(12): 1778 - 1796.

6. Hueckel T, Borsetto M. Thermoplasticity of saturated soils and shales. constitutive equations. Journal of geotechnical engineering 1990; 116(12):1765 - 1777.

7. Robinet JC, Rahbaoui A, Plas F, Lebon P. Constitutive thermomechanical model for saturated clays. Engineering Geology 1996; 41(1-4):145 - 169.

8. Graham J, Tanaka N, Crilly T, Alfaro M. Modified cam-clay modelling of temperature effects in clays. Canadian Geotechnical Journal 2001; 38(3):608 - 621.

9. Abuel-Naga H, Bergado D, Bouazza A, Ramana G. Volume change behaviour of saturated clays under drained heating conditions: Experimental results and constitutive modeling. Canadian Geotechnical Journal 2007; 44(8):942-956.

10. Laloui L, François. Acmeg-t: Soil thermoplasticity model. Journal of Engineering Mechanics 2009; 135:932-944.

11. Hujeux J. Calcul numérique de problèmes de consolidation élastoplastique. $\mathrm{PhD}$ Thesis, Ecole Centrale de Paris, Paris 1979.

12. Del Olmo C, Fioravante V, Gera F, Hueckel T, Mayor J, Pellegrini R. Thermomechanical properties of deep argillaceous formations. Engineering Geology 1996; 41(1):87-102.

13. Sultan N, Delage P, Cui Y. Temperature effects on the volume change behaviour of boom clay. Engineering Geology 2002; 64(2-3): $135-145$

14. Cekerevac C, Laloui L. Experimental study of thermal effects on the mechanical behaviour of a clay. International Journal for Numerical and Analytical Methods in Geomechanics 2004; 28(3):209-228. 
15. Abuel-Naga HM, Bergado DT, Bouazza A. Thermally induced volume change and excess pore water pressure of soft bangkok clay. Engineering Geology 2007; 89(1-2):144-154.

16. Campanella R, Mitchell J. Influence of temperature variations on soil behavior. Journal of the Soil Mechanics and Foundations Division, ASCE 1968; 94:709-734.

17. Baldi G, Hueckel T, Pellegrini R. Thermal volume changes of the mineral-water system in low-porosity clay soils. Canadian Geotechnical Journal 1988; 25(4):807 - 825.

18. Sultan N. Etude du comportement thermo-mécanique de l'argile de boom: expériences et modélisation. PhD Thesis, CERMES, ENPC, Paris 1997.

19. Wood D. Soil behaviour and critical state soil mechanics. Cambridge University Press, 1990.

20. Dafalias Y, Herrmann L. A bounding surface soil plasticity model. International Symposium on Soils under Cyclic and Transient Loading, Swansea, UK, vol. 1, 1980; 335-345.

21. Dafalias Y. Bounding surface plasticity. i: Mathematical foundation and hypoplasticity. Journal of Engineering Mechanics 1986; 112(9):966-987. 